\title{
Pattern analysis and distribution of the superior mesenteric artery branches in corpses in a death survey service
}

\author{
PEREIRA, A. K. F. T. C. ${ }^{1 *}$, AIRES NETO, S. A. ${ }^{2}$, SILVA NETO, E. J. ${ }^{1}$, \\ FRANCA, H. A. ${ }^{3}$, NEGROMONTE, G. R. P. ${ }^{3}$, LUCENA, R. R. L. ${ }^{3}$, \\ MAIA, A. D. ${ }^{3}$ and FRANCA, C. C. N. L. ${ }^{3}$
}

\author{
${ }^{1}$ Morphology Department, Health Sciences Center, Universidade Federal da Paraíba - UFPB, Av. Cidade \\ Universitária s/n - Campus I, Bairro Castelo Branco, CEP 58059-900, João Pessoa, PB, Brazil \\ ${ }^{2}$ Internal Medicine Department, Medical Sciences Center, Universidade Federal da Paraíba - UFPB, \\ Av. Cidade Universitária s/n - Campus I, Bairro Castelo Branco, CEP 58059-900, João Pessoa, PB, Brazil \\ ${ }^{3}$ Medical Sciences Center, Universidade Federal da Paraíba - UFPB, Av. Cidade Universitária s/n - Campus I, \\ Bairro Castelo Branco, CEP 58059-900, João Pessoa, PB, Brazil \\ *E-mail: anaodonto80@hotmail.com
}

\begin{abstract}
Introduction: The distribution pattern of the superior mesenteric artery (SMA) varies in the studies described by the literature. Objectives: To establish the variation pattern for the Brazilian population as well as to compare this distribution according to sex and ethnic groups. Materials and Methods: A total of 41 corpses were dissected in the Death Survey Service of Paraíba (SVO/PB), and the variation patterns were analyzed by comparing sex and ethnic groups by means of the statistical program SPSS 21.0. Results and Conclusion: From the 41 dissected corpses, $43,9 \%, n=18$ were classified as normal, standard type $1,7,3 \%, n=3$, standard type 2 , $24,3 \%, \mathrm{n}=10$, standard type $3,14,6 \%, \mathrm{n}=6$, standard type $4,9,7 \%, \mathrm{n}=4$, standard type $5,9,7 \%, \mathrm{n}=4$. Statistically significant variations of the SMA patterns in relation to sex and ethnic groups were not found. The described patterns should be verified in order to inform and lead the health professionals in relation to the patient's care, especially in the surgical scope.
\end{abstract}

Keywords: superior mesenteric artery, sex, ethnic groups.

\section{Introduction}

The anatomical normality pattern of the Superior Mesenteric Artery (SMA) has no consensus in literature and its description varies a lot among the authors. The SMA branching pattern for irrigation of the ascending and transverse colon, that articles and books mention as normal, is composed by the ileocolic arteries, whose purpose is the irrigation of the cecum and inferior portion of the ascending colon, right colic that is responsible for the nutrition of the middle portion of the ascending colon and the middle colic, superior irrigation of the ascending colon and part of the transverse one, that are branches of the right SMA side. (MOORE and DALLEY, 2011; SINNATAMBY, 2006).

In Chanpen's and Arjhansiri's study (CHANPEN and ARJHANSIRI, 2012), the commonest branching, normal pattern, corresponded to $81,8 \%$ of the found cases. International literature data state that the normality pattern occurs between 70-90\% (JAIN and MOTWANI, 2013; NIRMALADEVI, SESHAYYAN and RAJIILA, 2012). Despite that some studies disagreed with this proportion (IGIRI, EKONG, EGEMBA et al., 2010; SOBOTTA and BECHER, 2012), the pattern mostly found for the colon vascularization by the SMA represents approximately $24 \%$ of the cases. (SOBOTTA and BECHER, 2012).

These data infer that the variations in the distribution of the SMA branches are common. Some of the mostly found variations are: the right colic artery originating from the middle colic artery or ileocolic artery, inexistence of the right colic artery or the middle colic one, presence of a common trunk for the right colic and ileocolic arteries, the hepatic artery and the cystic artery arising in the SMA and the inferior mesenteric artery as SMA branch. (LANGE, KOMEN, AKKERMAN et al., 2007; IGIRI, EKONG, EGEMBA et al., 2010; OSAWA, FENG, SASAKI et al., 2004; YOO, KU, CHO et al., 2011).

Therefore, knowledge about the variations of the SMA branches is of great importance in order to avoid iatrogenies during surgical procedures and to minimize injuries in emergency situations.

With the study of seventy-five Nigerian corpses, Igiri, Ekong, Egemba et al. (2010) propose three variation patterns having the normality pattern reached $60 \%$, which is different from some published pieces of research.

According to Lufukuja (2014), the arterial variations and the accurate knowledge of the anatomic variations cannot be neglected, as many surgeries and their post-surgery complications can be avoided. Knowledge about the variations allows preventing unexpected injuries.

Feliciano (1990), Mullins, Huckfeldt and Trunkey (1996) mentioned the hemorrhagic shock as the commonest immediate cause of death in the sick patients with abdominal vascular lesions. During the initial evaluation of a traumatized patient in the emergency department, the surgeon should determine quickly if the patient has a potentially fatal intra-abdominal 
hemorrhage and deal, immediately, with the bleeding control. The surgeon should carry out three tasks immediately during the celiotomy for avoiding hemorrhage with exsanguination in the abdomen: a) Identification of the vessel location or the injured vessels; b) Surgical exposure of the traumatized vessels; c) Accomplishment of the hemostasis and restoration of the critical blood flow. The arteries or blood veins can be repaired or linked according to the surgeon's decision; and from this aspect, they are influenced by the benefits of the immediate hemostasis in comparison with the ischemia risks.

Therefore, knowledge about the variations of the SMA branches is of great importance in order to avoid iatrogenies during surgical procedures and to minimize injuries in emergency situations.

According to Sobotta and Becher (2012), the ileocolic artery represents a continuation of the superior mesenteric artery and not its branching. Other authors such as Busetti, Prates, Wafal et al. (1991), Dângelo and Fattini (2007) and Igiri, Ekong, Egemba et al. (2010) disagree with this statement, presenting the ileocolic artery as SMA branching in all cases and not the continuation of this artery.

In the face of different data in literature, the current work aims to analyze the variations of the superior mesenteric artery and compare them according to the sex and ethnic group once these data have not been related yet in a statistical analysis in previous studies. The study focused on the middle colic, the right colic and the ileocolic arteries.

\section{Materials and Methods}

The study was carried out in the Death Survey Service of Paraíba (SVO/PB) located at the Federal University of Paraíba, campus I, in João Pessoa, with the authorization of the institution and the research committee. The piece of research was in accordance with the Resolution 496/12 of the National Health Council in all its variants. An Informed Consent Form was signed by the family in each analysis. The study variables were sex, ethnic group and variation of the middle colic, left colic and ileocolic arteries. The sex, male and female, and the ethnic groups, white and non-white, were described according to the expert report registered by the physician on duty. The study of the variations was carried out by means of dissection and direct visualization.

The corpse was in supine position. Initially, incision from the chin to the pubis and evaluation of the cause of death were fulfilled, for the accomplishment of the expert report. Corpses with injuries in the superior mesenteric artery and its branches were excluded from the study. For the retroperitoneal access, the Cattell-Braasch maneuver was carried out. This consists of the right-sided medial visceral rotation (right flank) with retroperitoneal release of the common bile duct (CBD) to the suspensory muscle of the duodenum [Treitz], and it allows the identification of the structures of the inframesocolic compartment in which the mesenteric vessels are highlighted. The reference point for the SMA identification was the pancreas colon and the careful dissection to the origin in the abdominal aorta. Afterwards, the branches originated from the superior mesenteric artery were dissected, isolated with 2-0 cotton thread (Ethicon ${ }^{\circledR}$, Johnson \& Jonhson, São Paulo-Brazil), and designated according to the arterial pattern, type $\mathrm{l}=$ ascending and transverse colon irrigated by three branches as middle colic artery, right colic artery and ileocolic artery, type $2=$ four branches, being one middle colic artery and two right colic arteries and one ileocolic artery, type $3=$ two branches, being one middle colic and one ileocolic artery with absence of the right colic artery, and type $4=$ two main branches in which the superior will originate the middle colic artery and the inferior one to the common trunk of the right colic artery and the ileocolic one, type $5=$ the other variations which were not included in the reported specific pattern of variation. At the end of the dissection, all cases were photographed.

Data were tabulated in SPSS 21.0 for Windows. Descriptive analysis was carried out and the chi-squared test with correction for continuity was used. The $\mathrm{p}<0.05$ value was considered as statistically significant.

\section{Results}

A total of 41 corpses were dissected being $51.2 \%(n=21)$ male and $48.8 \%(n=20)$ female. In regard to the ethnic group, 43.9\% $(\mathrm{n}=18)$ non-white, $56.1 \%(\mathrm{n}=14)$ white.

Analyzing data in a descriptive way, we had the following distribution: type 1,18 cases, $43.9 \%$; type 2,3 cases, $7.3 \%$; type 3 , 10 cases, $24.3 \%$; type 4,6 cases, $14.6 \%$; type 5 , 4 cases, $9.7 \%$.

In relation to the arterial pattern, the predominant casuistry was the type 1 with $43.9 \%$ (Figure 1 ). When we compared the arterial pattern between the sexes, the types 1 and 3 present higher variations (Figure 2). When we compared the arterial pattern between the ethnic groups, it is observed that the type 1 is more frequent in the white ethnic group and the type 3 in the non-white ethnic group (Figure 3).

The relation between the sex (male and female) and the arterial pattern (normal or variation) did not present significant relation, $\mathrm{p}=0.279$. For this reason, accordingly to the relation between the ethnic groups, the arterial pattern also did not present significant relation $\mathrm{p}=0.128$.

The identified normality pattern is below the one described in literature, in which such pattern is found around $80 \%$ of the cases. The normality percentages found in the study of authors such as Jain and Motwani (2013), of 70\%, Igiri, Ekong, Egemba et al. (2010), of 60\%, Chanpen and Arjhansiri (2012),

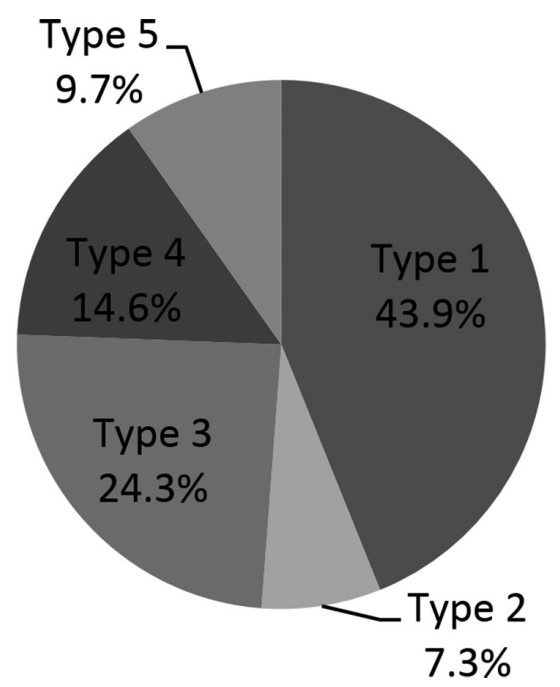

Figure 1. Arterial pattern percentage according to the proposed classification. 


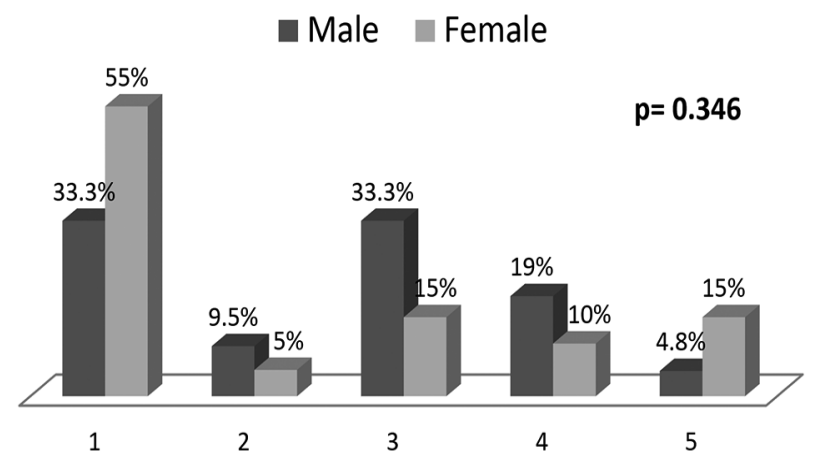

Figure 2. Comparison of the arterial pattern according to the sex.

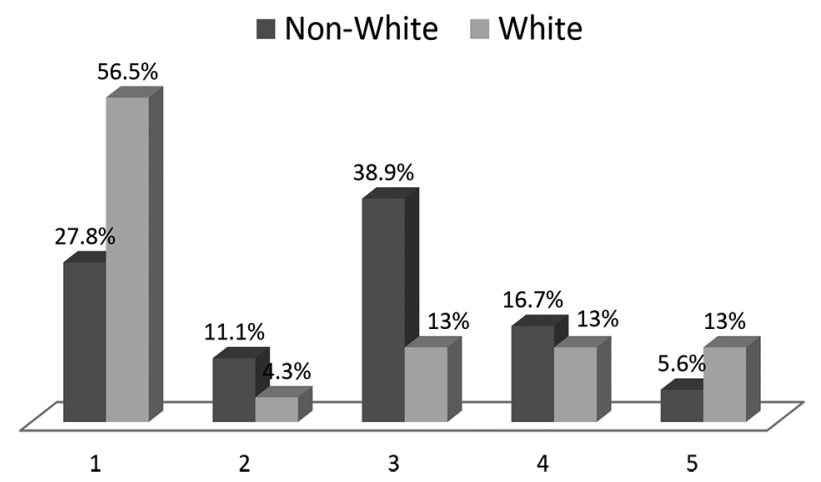

Figure 3. Comparison of the arterial pattern according to the ethnic group.

of $81.8 \%$ and Nirmaladevi, Seshayyan and Rajiila (2012), of $86 \%$ do overcome the values found in this study and the data described in Sobotta and Becher (2012) of 24\% are below the shown results. The type four pattern with $14.6 \%$ was close to the same variation found by Jain and Motwani (2013), having been described in $25 \%$ of the cases (Table 1 )

In spite of Sobotta and Becher (2012) and Wolf-Heidegger (2006) have highlighted the ileocolic artery as SMA continuation, in all cases of our study this artery arose as SMA branching. This is corroborated by the study of Busetti, Prates, Wafae et al. (1991), that describes having found in $100 \%$ of the cases, 116 corpses, the ileocolic artery arising from the right side of the SMA and not as its continuation.

Despite the type 1 and type 3 variations present differences in regard to sex and ethnic group, these were not statistically significant. Nirmaladevi, Seshayyan and Rajiila (2012), in a study in South Africa, found normality pattern similar to the one in the international literature, having the piece of research been carried out in a group with similar racial and ethnic characteristics between themselves and different from other areas of the world. This datum validates the non-significant statistical analysis of the arterial pattern according to the ethnic group found in this study. The variation of the arterial pattern in accordance with sex was not also statistically significant. Other studies may confirm these results once there have not been found other articles that mention, in statistical analysis, the relation between arterial pattern and race and arterial pattern and sex.
Table 1. Table of the SMA pattern.

\begin{tabular}{lccc}
\hline & NORMAL & VARIATIONS & $\begin{array}{c}\text { N OF THE } \\
\text { STUDY }\end{array}$ \\
\hline Study & $43.9 \%$ & $56.1 \%$ & \\
\hline $\begin{array}{l}{ }^{1} \text { Igiri, Ekong, } \\
\text { Egemba et al. } \\
(2010)\end{array}$ & $60 \%$ & $40 \%$ & 75 \\
\hline $\begin{array}{l}{ }^{2} \text { Jain and } \\
\text { Motwani } \\
(2013)\end{array}$ & $70 \%$ & $30 \%$ & 20 \\
\hline $\begin{array}{l}3 \text { Chanpen } \\
\text { and Arjhansiri } \\
(2012)\end{array}$ & $81.8 \%$ & $18.2 \%$ & 163 \\
\hline $\begin{array}{l}{ }^{4} \text { Nirmaladevi, } \\
\text { Seshayyan and } \\
\text { Rajiila (2012) }\end{array}$ & $86 \%$ & $14 \%$ & 50 \\
$\begin{array}{l}\text { Sobotta and } \\
\text { Becher (2012) }\end{array}$ & $24 \%$ & $76 \%$ & \\
\hline
\end{tabular}

${ }^{1}$ Study carried out in Nigeria. ${ }^{2}$ Study carried out in India. ${ }^{3}$ Study carried out in Thailand. ${ }^{4}$ Study carried out in South Africa.

\section{Conclusion}

The normality pattern was found in $43.9 \%$ of the cases, followed by the type three variation, demonstrating to be the most prevalent variation. Taking into account the dissenting data in literature, more pieces of research should be carried out by increasing the $N$ of the researching field. As proposed in other articles, the ileocolic artery was found as SMA branching in all cases. Significant statistical variations of the superior mesenteric artery, according to the sex and ethnic group, were not found. As such analysis was not found in other articles, it is suggested that other studies with different populations and casuistries may be analyzed by means of statistical analysis.

\section{References}

BUSETTI, JH., PRATES, JC., WAFAE, N., OLIVEIRA, FM. and ALFABET, C. A artéria apendicular (nota prévia). Arquivos Médicos do $A B C, 1994$, vol 17, n. 1-2, p. 9-11.

CHANPEN, N. and ARJHANSIRI, K. Aberrant branches of the superior mesenteric artery detected by MDCT angiography of abdominal aorta. Asian Biomedicine, 2012, vol. 6, n. 2, p. 219-226.

DÂNGELO, JG. and FATTINI, CA. Anatomia humana sistêmica e segmentar. 3rd ed. São Paulo: Atheneu, 2007.671 p.

FELICIANO, DV. Management of traumatic retroperitoneal hematoma. Annals of Surgery, 1990, vol. 211, n. 2, p. 109-123.

IGIRI, AO., EKONG, MB., EGEMBA, GO. and ASUQUO, RO. The pattern of arrangements and distributions of the superior mesenteric artery in a Nigerian population. International Journal of Morphology, 2010, vol. 28, n. 1, p. 33-36.

JAIN, P and MOTWANI, R. Morphological Variations of superior mesenteric artery: a cadaveric study. International Journal of Anatomy and Research. International Journal of Anatomy and Research, 2013, vol. 1, n. 2, p. 83-87.

KOPF-MAIER, P. Wolf-Heidegger: atlas de anatomia humana. 6. ed. Rio de Janeiro: Guanabara Koogan, 2006.

LANGE, JF., KOMEN, N., AKKERMAN, G., NOUT, E., HORSTMANSHOFF, H., SCHLESINGER, F., BONJER, J. and 
KLEINRENSINK, G. Riolan's arch: confusing, misnomer, and obsolete. A literature survey of the connection(s) between the superior and inferior mesenteric arteries. American Journal of Surgery, 2007, vol. 193 , n. 6 , p. $742-748$.

LUFUKUJA, GJ. A variant origin of cystic artery from superior mesenteric artery. International Journal of Variations, 2014, vol. 7, p. 30-31.

MOORE, KL. and DALLEY, AF. Anatomia orientada para a clinica. 6th ed. Rio de Janeiro: Guanabara Koogan, 2011. 1104 p.

MULLINS, RJ., HUCKFELDT, R. and TRUNKEY, DD. Abdominal Vascular Injuries. The Surgical Clinics of North America, 1996, vol. 76, n. 4 , p. 813-832.

NIRMALADEVI, M., SESHAYYAN, S. and RAJIILA, HSR. Study of origin of mesenteric artery in South Indian population- Original study with review of literature. Anatomica Karnataka, 2012, vol. 6, n. 2 , p. 33-37.
OSAWA, T., FENG, X., SASAKI, N., NAGATO, S., MATSUMOTO, Y., ONODERA, M., NARA, E., FUJIMURA, A. and NOZAKA, Y. Rare case of the inferior mesenteric artery and the common hepatic artery arising from the superior mesenteric artery. Clinincal Anatomy, 2004, vol. 17, n. 6, p. 518-21.

SINNATAMBY, CS. Last's Anatomy: regional and applied. 11th ed. Edinburgh: Elsevier, 2006.

SOBOTTA, J. and BECHER, H. Atlas de Anatomia humana: órgãos internos. 23rd ed. Rio de Janeiro: Guanabara Koogan, 2012. 264 p.

YOO, SJ., KU, MJ., CHO, SS. and YOON, PS. A case of inferior mesenteric artery arising from the superior mesenteric artery. Journal of Korean Medical Science, 2011, vol. 26, n. 10, p. 1382-1385.

Received August 10, 2014 Accepted April 14, 2016 